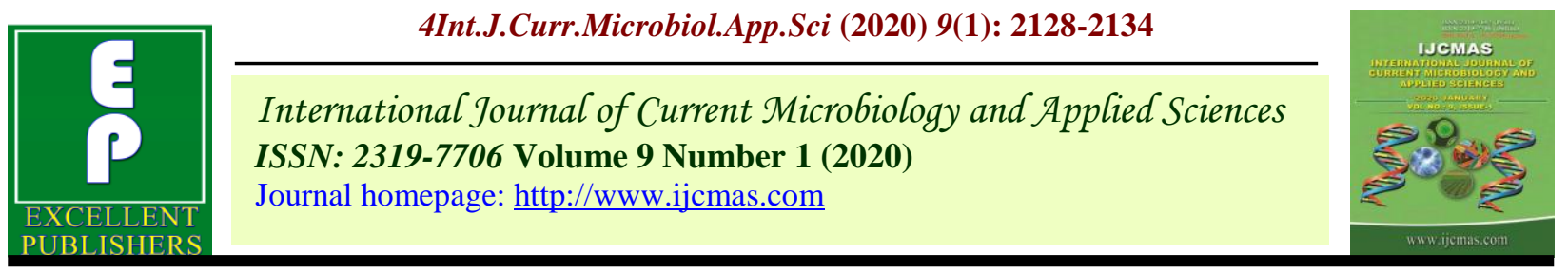

Original Research Article

https://doi.org/10.20546/ijcmas.2020.901.242

\title{
A Prevalence Study on Bacteriological Profile and Antimicrobial Resistance of Bacterial Isolates from Medical Intensive Care Unit in a Tertiary Care Hospital
}

\author{
M. A. Ashiha Begum*, R. Shanthi and Jeyamathi \\ Tirunelveli Medical College, Tirunelveli - 627011, India
}

\begin{tabular}{|c|}
\hline Keywords \\
\hline $\begin{array}{l}\text { Nosocomial } \\
\text { infection, BSI, UTI, } \\
\text { Antibiogram, } \\
\text { Antimicrobial, } \\
\text { Resistance patterns } \\
\text { (AMR), Intensive } \\
\text { Care Unit }\end{array}$ \\
\hline Article Info \\
\hline $\begin{array}{l}\text { Accepted: } \\
15 \text { December } 2019 \\
\text { Available Online: } \\
20 \text { January } 2020\end{array}$ \\
\hline
\end{tabular}

\section{A B S T R A C T}

Studies throughout the world document that the nosocomial infections are a major cause of morbidity and mortality. Many factors contribute to the frequency of nosocomial infections like immunocompromised state of patients, invasive examinations and treatments, patient care practices and hospital environment which facilitate transmission of microbes among patients. Treatment is becoming difficult due to inappropriate use of antibiotics and hence resistance develops. Knowledge on antibiotic resistance pattern is essential for appropriate therapy. Objectives of the study are to evaluate the bacteriological profile causing Blood Stream and Urinary Tract Infections in a medical Intensive Care Unit. 2. To analyse the antibiotic susceptibility tests and hence to arrive the Antimicrobial resistance patterns from ICU patients. Blood samples and urinary samples from adult patients of both sexes admitted to ICU, for a period of six months, acquiring signs of sepsis will be analysed by blood culture done in BHI broth and MSU sample of urine collected and process in CLED media. Culture positives identified by growth in the selective media, confirmed by Biochemical tests and Antibiotic susceptibility tests done in Muller Hilton Agar by Kirby Bauer's disc diffusion method. Hence Antimicrobial resistance profiles of bacterial strains were analysed. Total of 43 BSI and 296 urinary positive samples were obtained from Medical ICU over a period of six months in Apr- Sep 2019.The most prevalent BSI pathogens were Klebsiella pneumoniae, Staphylococcus aureus and CoNS Escherichia coli and Klebsiella spp. being the prevalent pathogens from urinary tract samples. The antimicrobial resistance profile from ICU patients were analysed for generating Antibiogram in a Tertiary care hospital. Vancomycin, Merapenam, Imipenam, Linizolid, Cefiperazone /Salbactum are most effective antibiotics against Gram positive bacteria. Amikacin, Gentamycin, Piperacillin/ Tazobactum and Nitrofurantoin are effective against nosocomial UTI infection caused by Gram negative bacteria. This study also guides to formulate Antibiotic policy which helps the Clinician to choose empirical therapy and switch over to for Escalation and Cycling of Antibiotics which favours Infection control methods. 


\section{Introduction}

Hospital acquired infections (HAI) are usually defined in any critical areas like ICU associated infections that occur after 48 to 72 hours of ICU admission or within 48 hours after transfer from an ICU as per $\mathrm{CDC}^{7}$ (Centre for Disease ${ }^{6}$ Control prevention). HAIs are important public health problem, both in developing and developed countries ${ }^{1}$. The most important nosocomial infections are urinary tract infection, surgical-wound infection, pneumonia, blood stream infections ${ }^{8}$. BSIs are responsible for approximately $17-22 \%{ }^{6,7}$. UTI is a presence of bacteria in urine (bacteriuria) and defined as the growth of a single pathogen of $>10^{5}$ colony forming units/mL of properly collected mid-stream urine samples ${ }^{3}$. The common bacterial pathogens in BSI and UTI Staphylococcus aureus, Coagulase-Negative Staphylococci, Klebsiella pneumoniae, Escherichia coli, Pseudomonas aeruginosa, Enterobacter spp., Acenietobacter spp., Enterococcus spp. and Proteus $\mathrm{spp}^{5,13}$. As there is inappropriate use of antimicrobial agents, nosocomial pathogens have shifted from easily treatable ones to more resistant bacteria $^{4}$. This is a challenge for nosocomial infection control methods. Critical area specific studies are aimed to gain knowledge about pathogen profile, antimicrobial resistance patterns which can minimise mobility and mortality rates by optimising treatments guideline ${ }^{4,15}$. As there is limited data in our centre, this study was undertaken to define the bacterial pathogens in BSI and UTI and to analyse the antimicrobial resistance patterns which guides for formulating Antibiotic policy.

The main objectives of this study include to evaluate the bacteriological profile causing BSI and UTI in Medical Intensive Care Unit. And to study the Antibiotic Susceptibility tests and hence to analyse the Antimicrobial
Resistance patterns of bacterial isolates from ICU patients.

\section{Materials and Methods}

Study Period : $\quad 6$ months
Study design : $\quad$ Prevalence Study
Sample size $: \quad 208$ blood cultures and
995 urinary tract samples

This Cross sectional study was conducted in the Medical Intensive Care Unit patients of a Tertiary care hospital in South India. Adult patients who are admitted in Medical ICU, of 18 years and above, both sexes presenting with at least two clinical signs of infection like fever, hypotension, tachycardia and increase in respiratory rate, after 48 hours of admission to the ICU were included.

Patients showing clinical signs of infections prior to admission or transfer from ICU to inpatient wards were excluded. Patients admitted for short term post-operative monitoring were excluded. After obtaining Institutional Ethical Committee clearance the analysis was done.

\section{Study tool}

Only Bacterial HAIs were included by methodologies like one Blood culture and Urine culture were processed by the routine culture methods and biochemical identification. For blood culture-5 $\mathrm{ml}$ of blood was collected by aseptic precautions from each patient and inoculated into $50 \mathrm{ml}$ Brain Heart Infusion (BHI) broth. For Urine culture, midstream urine (MSU) sample inoculated into Cystene Lysine Electrolyte Deficient (CLED) media and culture done and identified by growth and biochemical tests. The bacterial isolates were subjected to Antibiotic susceptibility test (AST) in Muller Hinton Lawn culture, using Kirby Bauer's disk diffusion method as per CLSI guidelines 
using various antibiotic disks like Amikacin, Gentamycin, Cefotazime, Ceftriazone, Cefepyraxone/Sulbacatum, Piperacillin/ Tazobactum, Merapenam, Imipernam, Vancomycin, Amoxyclauv, Cotrimoxazole, Nitrofurantoin, Linezolid and Norfloxacinfor evaluating Antimicrobial Resistance (AMR) patterns.

\section{Statistical analysis}

Data entry and statistical analysis were performed using SPSS v.13 software and comparisons were made using Chi-square Methods. A value $<0.05$ was considered indicative of statistically significant difference.

\section{Results and Discussion}

\section{Nosocomial BSI}

A total of 208blood samples received from suspected BSI were analysed. Among them $42(19.2 \%)$ were documented as BSI of monomicrobial in nature. Of the 42 patients $20(47.3 \%)$ were females and $22(52.7 \%)$ were males. Klebsiella pneumoniae (38.6\%) and Staphylococcus aureus (29.4\%) were the prevalent organisms from nosocomial BSI patients followed by CoNS (18.2\%), Acinetobacter (7.1\%), P. aeruginosa (4.7\%), Strepto. pneumoniae (2.1\%).

No significant differences among both genders were noted ${ }^{9}$. Highest resistance rate for Staphylococcus aureus and CoNS was against Penicillin and Ampicillin and lowest rate of resistance was against Vancomycin and Linezolid and Cefepyrazone /Sulbacatum. The Gram negative bacteria showed lowest resistance to Cefepyrazone /Sulbactum, Pip/ Taz, Ceftazidime, Cefotaxine, Cotrimoxazole, Nitrofurantoin, Gentamycin, Amikacin and highest resistance to Penicillin, Erythromycin, Tetracycline.

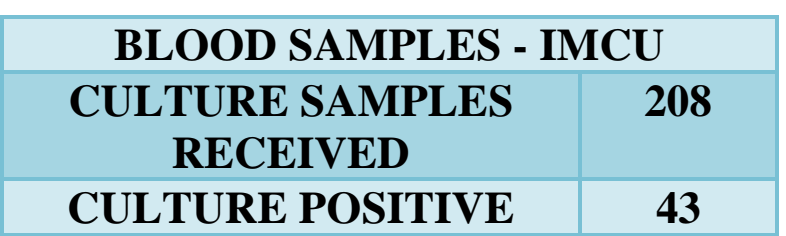

\section{Nosocomial UTI}

A total of 975 urine samples were processed in CLED media and 296 samples identified as culture positive and confirmed by battery of biochemical tests. Among them 201(68\%) were females and 95 (32\%)were males ${ }^{9}$ (mean age 45.8, range: $18-80$ yrs) E.coli (46.4\%) of the most common Gram-negative bacilli isolated from nosocominal UTI followed by Klebsiella spp. (29.7\%), Staph. aureus (11.4\%), CoNS (3.6\%), Proteus (3\%), Pseudomonas (3\%), Citrobacter (2\%), Enterococcus (1\%), Enterobactor (1\%).

Many of HAIs are associated with pathogens showing selective pressure for different antibiotics and hence develops resistance by inappropriate antibiotics usage and spread easily in hospital surroundings ${ }^{6,13,14}$.

The prior studies show most common organism indicative of polymicrobial in nature - Staph. aureus, CoNS, Enterococcus, Streptococcus pneumoniae among Gram positive bacteria. Among Gram negative bacteria Klebsiella, E. coli, Acinetobacter baumannii, Enterobacter cloacae and Pseudomonas aeruginosa of multi drug resistance (MDR) strains ${ }^{3,8}$.

Our study shows distribution of bacterial strains isolated from nosocomial BSI and UTI in a tertiary care hospital and their resistance patterns are discussed. A study in Brazil revealed predominance of Staph. aureus followed by E.coli, Klebsiella. In our study among BSI patients Gram-negative bacteria like Klebsiella, Escherichia coli were more regularly isolated than Gram-positive 
bacteria. This finding is an accordance with the results of recent studies done in many countries $^{10,12}$.

Our data shows highest resistance of Staphylococcus aureus and CoNS was against Penicillin followed by Ampicillin in Methicillin resistant staphylococcus species. In this study E.coli strains isolated from BSI patients showed higher resistance to Tetracycline and Ampicillin which is similar to a study from Ireland ${ }^{1,2}$. In our study $6.7 \%$ Acinetobacter species shows high resistance to Cotrimoxazole and Gentamycin, Ciprofloxin. Re-emergence of Acinetobacter spp. bacteraemia increasing especially from Asian countries Iran, Iraq and Afghanistan.
The present study shows Vancomycin, Cefiperaxone / Sulbactum and Merapenam are most effective antibiotic against Staphylococcus aureus and CoNS organisms. This is in agreement with many recent studies.

In our study the statistical analysis showed a significant correlation between nosocomial UTI prevalence among females. This could be explained by a higher prevalence of UTI in women than men due to anatomical and physiological variations and E.coli is still the most common Gram negative organism in nosocomial UTI, which is consistent with the other studies from Asian countries.

Table.1 IMCU-Blood

\begin{tabular}{|c|c|c|c|c|c|c|c|c|c|c|c|c|c|c|c|c|c|}
\hline \multirow[t]{2}{*}{ S.No. } & \multirow[t]{2}{*}{ Organism } & \multicolumn{2}{|c|}{ COT } & \multicolumn{2}{|c|}{ AMP } & \multicolumn{2}{|c|}{ AK } & \multicolumn{2}{|c|}{ CIP } & \multicolumn{2}{|c|}{ GEN } & \multicolumn{2}{|c|}{ MERP } & \multicolumn{2}{|c|}{ CEF/SUL } & \multicolumn{2}{|c|}{$\mathbf{P} / \mathbf{T}$} \\
\hline & & $\mathbf{S}$ & $\mathbf{R}$ & $\mathbf{S}$ & $\mathbf{R}$ & $\mathbf{S}$ & $\mathbf{R}$ & $\mathbf{S}$ & $\mathbf{R}$ & $\mathbf{S}$ & $\mathbf{R}$ & $\mathbf{S}$ & $\mathbf{R}$ & $\mathbf{S}$ & $\mathbf{R}$ & $\mathbf{S}$ & $\mathbf{R}$ \\
\hline 1 & IED & $\mathbf{0}$ & 100 & 0 & 100 & 85 & 15 & 50 & 50 & 35 & 65 & 60 & 40 & 100 & $\mathbf{0}$ & 100 & $\mathbf{0}$ \\
\hline 2 & E.Coli & $\mathbf{0}$ & 100 & $\mathbf{0}$ & 100 & 100 & $\mathbf{0}$ & 75 & 25 & 100 & $\mathbf{0}$ & 100 & $\mathbf{0}$ & 100 & $\mathbf{0}$ & 90 & $\mathbf{0}$ \\
\hline
\end{tabular}

Fig.1 Klebsiella-sensitivity pattern IMCU-Blood

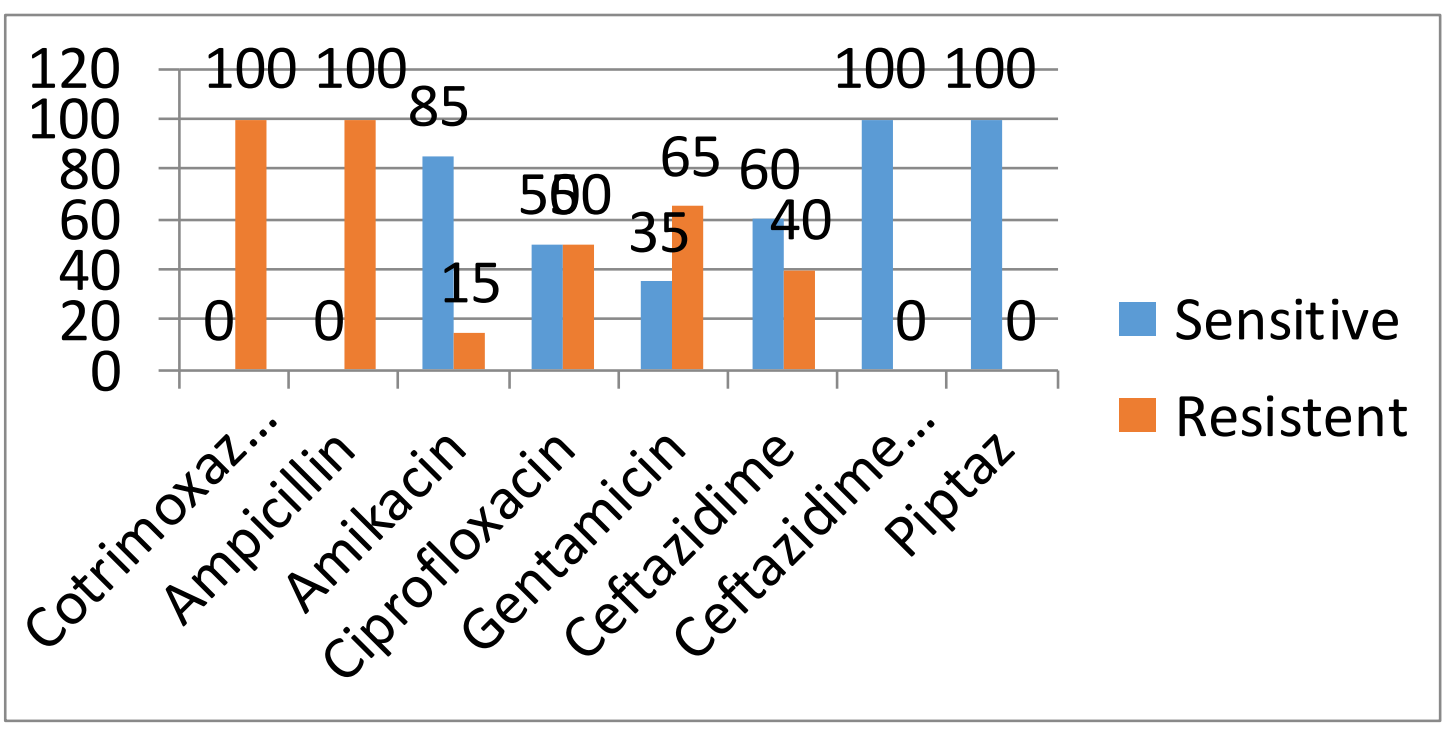


Fig.2 S. aureus-sensitivity pattern Blood-IMCU

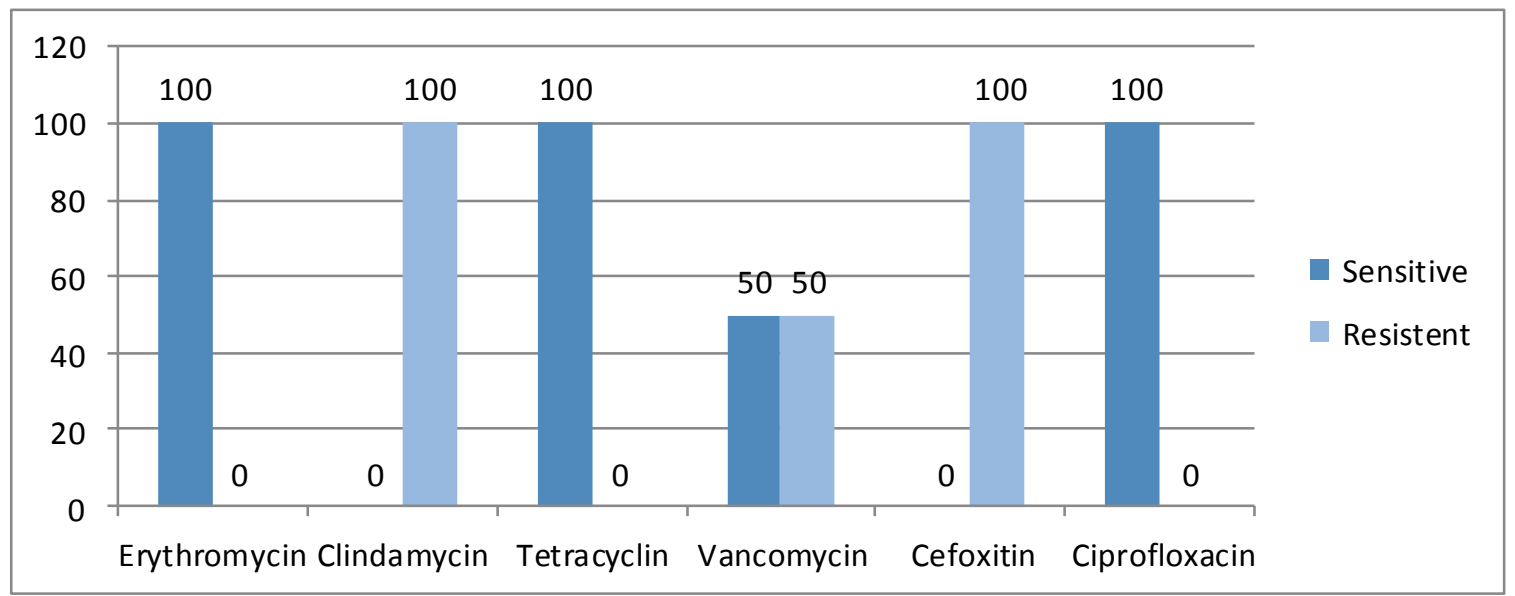

Fig.3

\section{Urinary Pathogens Profile From ICU Urine Samples}

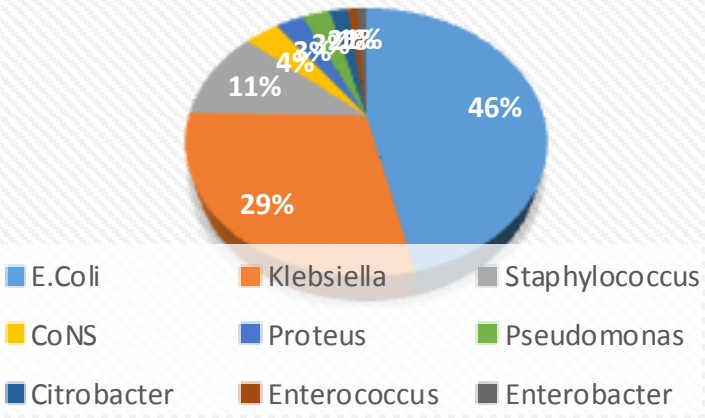

Fig.4 E. coli-sensitivity pattern urine-IMCU

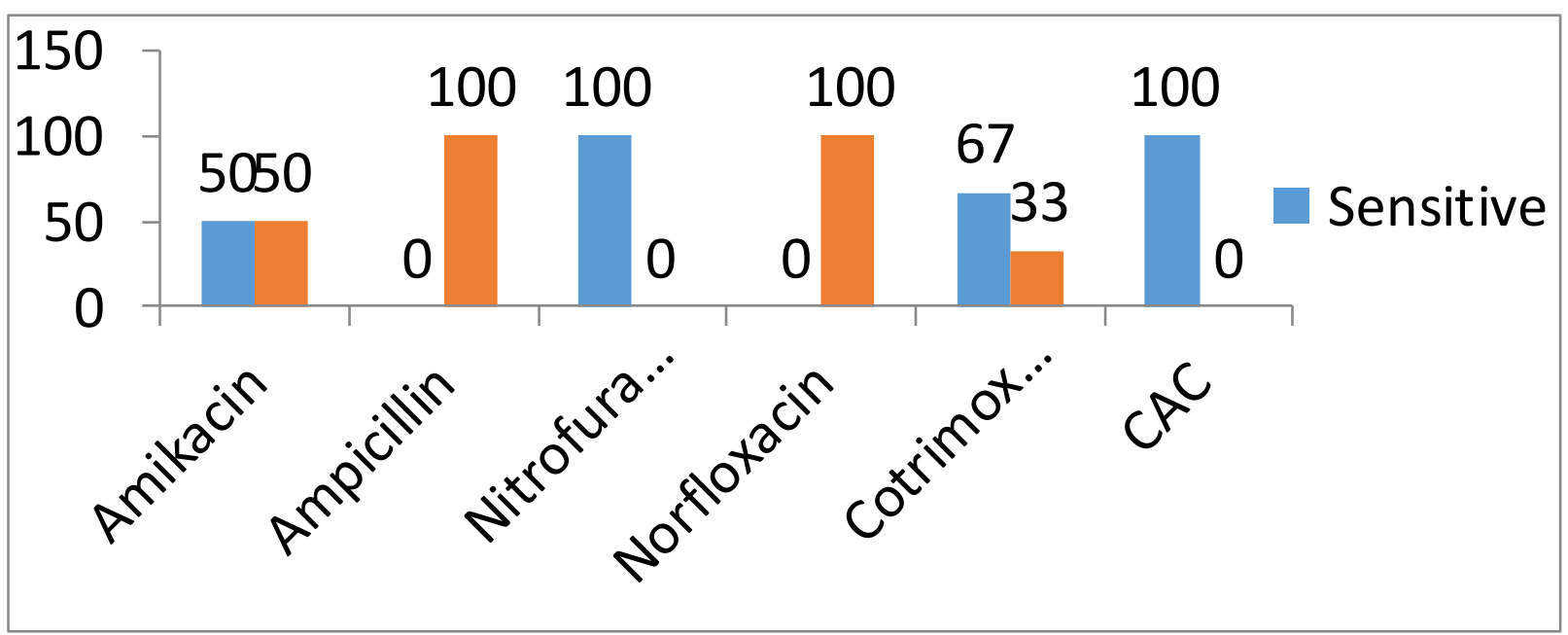


Fig.5 Klebsiella-sensitivity pattern urine-IMCU

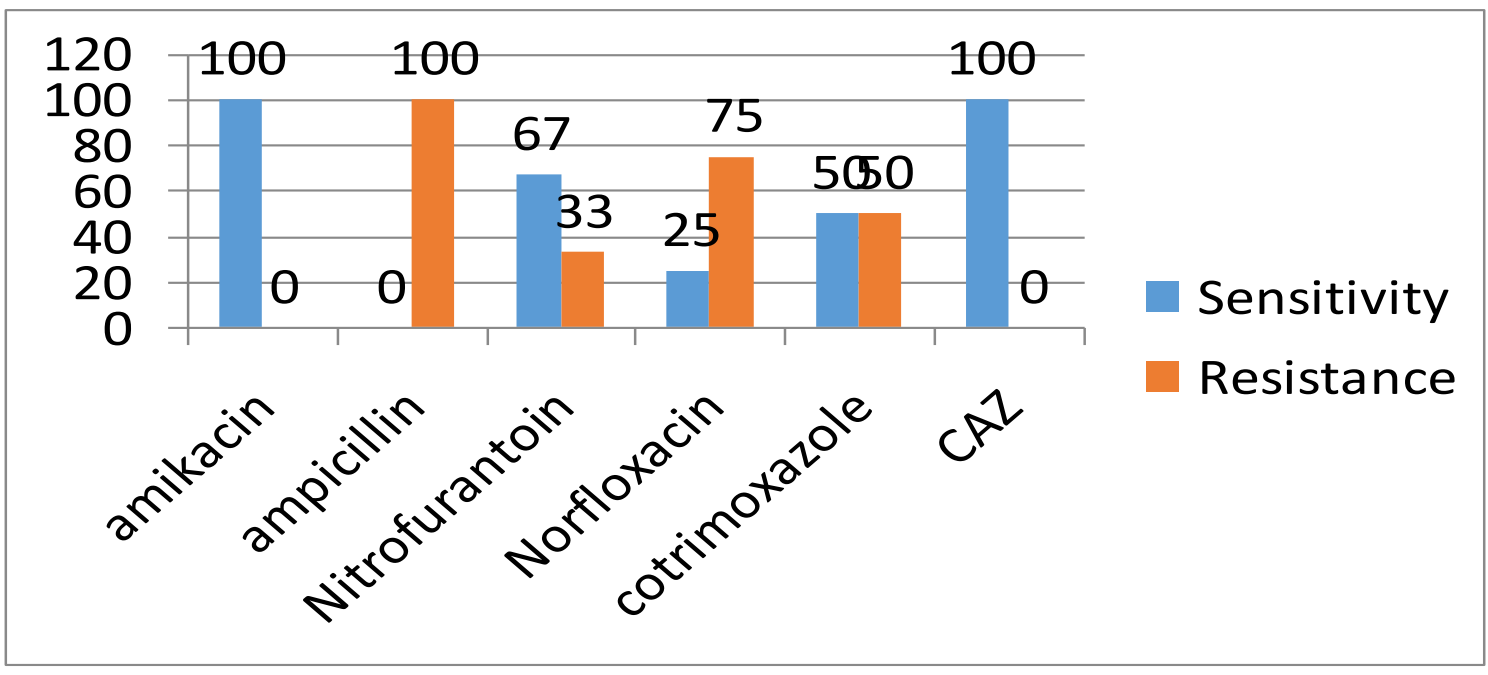

The higher resistance rate of E.coli isolates were against Cotrimoxazole, Ampicillin, and Norfloxacin and Amikacin. Cefiperaxone/ Sulbatum, Pip-Taz, Ciprofloxacin showed highest sensitivity against E.coli and Klebsiella isolates.

In conclusion, the rise of nosocomial BSI and UTI in ICUs patients due to interactions of several factors such as primary disease and its severity, duration of hospital stay and treatment and invasive interventions like use of catheters ${ }^{5,12}$ :

It is concluded from our study Gram-negative bacteria were most frequently involved in nosocomial BSI and UTI than Gram-positive bacteria ${ }^{9}$ Vancomycin, Linezolid and Cefiperazone /Subactum most effective antibiotics against Gram-positive bacteria and Gentamycin, Amikacin and Imipenem, Piptaz, Cefiperazone /Subactum proposed for nosocomial UTI treatments caused by $E$. coli followed by Klebsiella ${ }^{8}$.

Hence the present study suggestions includes AMR surveillance derived by doing Antibiotic sensitivity tests helps the center to generate Antibiogram which guides to formulate Antibiotic policy which is crucial in implementing Infection Control programmes. Also AMR patterns guides the Clinicians to choose appropriate therapy and assist escalation and cycling of antibiotics in establishing Antimicrobial stewardship, and thus helps for regulating infection control methods.

\section{Acknowledgement}

We are thankful to the HOD \& Staffs of Department of Medicine, Kaniyakumari Govt Medical College for their immense support for completing the study.

\section{References}

1. B. Forbes, D. Sahm, and A. Weissfeld, Bailey Scootts Diagnostic Microbiology Text and study Guide Package, Elsevier, New York NY, USA, $12^{\text {th }}$ edition, 2007

2. C. Mohan, D. Lehman, and G. Manuselis, Text Book of Diagnostic Microbiology, Elsevier, New York, NY, USA, $4^{\text {th }}$ edition, 2001

3. M.A. Saradi, M. Bayasallar , and H, Gun, "Nosocomial uropathogens and their antibiotic susceptibilities in a Turkish 
Military Hospital: a prospective and microbiological study," Turkish journal of medical sciences, vol.29,no.2,pp.165$168,1999$.

4. B. Durmaz, R. Durmaz, B. Otlu and E. Sonmez 'Nosocominal infections in a new medical center, Turkey,' Infection control and hospital Epidemiology, vol .21, no.8, pp.534-0538,2000

5. B. Pourakbari, A. Sadr, M.T. Ashitani et al., Five year evaluation of the antimicrobial susceptibility patterns of bacteria causing bloodstream infections in Iran," journal of infections in Developing countries, vol. 6 ,no.2, pp.120-125,2012.

6. A.R. Marra, L.F.A. Camargo, A.C.C. Pignatari et al., Nosocomial bloodstream infections in Brazilian hospitals: analysis of 2,563 cases from a prospective nationwise surveillance study. Journal of clinical microbiology, vol. 49, no. 5, pp. 1866-1871, 2001.

7. P. Mitt, V. Adamson, K. Lovukene et al., "Epidemiology of nosocomial bloodstream infections in Estonia." journal of hospital infection, vol. 71, no. 4. pp. 365-370, 2009.

8. S. Moyo, S. Aboud, M. Kasubi and S.Y. Maselle,'Bacteria isolated from bloodstream infections at a tertiary hospital in Dar es Salaam, Tanzaniaantimicrobial resistance of isolates," South African Medical journal, Vol. 100, no. 12, pp. 835-838, 2010.

9. M. Richards, K. Thursky, and K. Busing. Epidemiology prevalence, and sites of infections in intensive care units," seminars ain Respiratory and critical care medicine, vol.24,no.1, pp.22,2003

10. D. J. Diekema, M. A. Pfaller, R. N. Jones et al., Trends in antimicrobial susceptibility of bacterial pathogens isolated from patients with bloodstream infections in the USA, Canada and Latin America," International journal of Antimicrobial Agents, vol. 13, no. 4. pp. 257-271, 2000.

11. S. Kumar, M, Rizvi, S, Vidhani, and V. K. Sharma," Changing face of septicaemia and increasing drug resistance in blood isolates," Indian journal of pathology and microbiology, vol. 47, no. 3, pp. 441-446, 2004.

12. C.C.I. Kang, S.H. Kim, B.P. Waa et al., Bloodstream infections caused by antibiotic - resistant gram negative bacilli risk factors for mortality and impact of inappropriate agents and chemotherapy, vol. 49, no. 2, pp. 760-766, 2005.

13. A, Jain, A, Awasthi, and M. Kumar. Etiological and antimicrobial susceptibility profile of nosocomial blood stream infections in neonatal intensive care unit," Indian journal of medical microbiology, vol. 25, no. 3, pp. 146-155, 2000.

14. E.H. Ibrahim, G. Sherman, S. Ward, V.J. Frader and M.H. Kollef, "The influence of inadequate antimicrobial treatment of bloodstream infections on patient outcomes in the ICU setting," Chest, vol.118, no. 1, pp. 146-155, 2000.

15. WHO Ed, Prevention of HAI a practical guide, WHO Press, Geneva Switzerland $2^{\text {nd }}$ edition 2002.

\section{How to cite this article:}

Ashiha Begum, M. A., R. Shanthi and Jeyamathi. 2020. A Prevalence Study on Bacteriological Profile and Antimicrobial Resistance of Bacterial Isolates from Medical Intensive Care Unit in a Tertiary Care Hospital. Int.J.Curr.Microbiol.App.Sci. 9(01): 2128-2134. doi: https://doi.org/10.20546/ijcmas.2020.901.242 